\title{
Epidemiological Characterization of Colistin and Carbapenem Resistant Enterobacteriaceae in a Tertiary: A Hospital from Anhui Province
}

This article was published in the following Dove Press journal: Infection and Drug Resistance

\author{
Muhammad Fazal Hameed (D) \\ Yanan Chen' \\ Ying Wang ${ }^{2}$ \\ Muhammad Shafiq $\mathbb{D}^{3}$ \\ Hazrat Bilal' \\ Linqing $\mathrm{Liu}^{4}$ \\ Jinming $\mathrm{Ma}^{\mathrm{I}}$ \\ Pengying $\mathrm{Gu}^{4}$ \\ Honghua $\mathrm{Ge}\left(\mathbb{D}^{1}\right.$ \\ 'Institutes of Physical Science and \\ Information Technology, Anhui \\ University, Hefei, Anhui, 23060I, People's \\ Republic of China; ${ }^{2}$ Department of \\ Laboratory Medicine, The First Affiliated \\ Hospital of USTC, Division of Life \\ Science and Medicine, University of \\ Science and Technology of China, Hefei, \\ Anhui, 230036, People's Republic of \\ China; ${ }^{3}$ College of Veterinary Medicine, \\ Nanjing Agricultural University, Nanjing, \\ 210095, People's Republic of China; ${ }^{4}$ The \\ Department of Geriatrics, The First \\ Affiliated Hospital of USTC, Division of \\ Life Sciences and Medicine, University of \\ Science and Technology of China, Hefei, \\ Anhui, 230036, People's Republic of \\ China
}

Correspondence: Honghua Ge Institutes of Physical Science and Information Technology, Anhui University, Hefei, Anhui, 23060I, People's Republic of China

Tel +86-55I-6386I I73

Email hhge@ahu.edu.cn

Pengying Gu

The Department of Geriatrics, The First Affiliated Hospital of USTC, Division of Life Sciences and Medicine, University of Science and Technology of China, Hefei, Anhui, 230036, People's Republic of China Email hellengpy@I63.com
Purpose: Antimicrobial resistance, especially carbapenem resistance Enterobacteriaceae and plasmid mediated mobile colistin resistance, is a serious issue worldwide. This study was designed to determine the epidemiological characteristics of plasmid mediated colistin resistance and carbapenem resistant Enterobacteriaceae from tertiary A hospital located in Hefei, China.

Methods: Totally, 158 carbapenems resistant Enterobacteriaceae (CRE) were screened for antibiotic susceptibility, $m c r$ - 1 , extended spectrum $\beta$-lactamases (ESBLs), metallo- $\beta$ lactamases (MBLs), and fosfomycin resistance genes using PCR and sequencing. The sequence types were identified by multilocus sequence typing (MLST). Plasmid profiles were determined by PCR based replicon typing (PBRT), and the plasmid sizes were confirmed by southern blotting.

Results: The isolates showed high $\mathrm{MIC}_{50}$ and $\mathrm{MIC}_{90}$ for all antimicrobials, except tigecycline, meropenem, and colistin. The main Carbapenemase genes were $b l a_{\mathrm{KPC}-2}(90.5 \%), b l a_{\mathrm{NDM}-1}$ (3.7\%), bla $a_{\mathrm{OXA}-48}(5.6 \%)$ and fos 33 (14.5\%). The bla CTXM-15 $_{\text {found } 36.7 \% \text {, mcr-1 }}(3.7 \%)$ recorded in six isolates. PBRT revealed $b l a_{\mathrm{KPC}-2}$ in $K$. pneumoniae on IncR, IncFII, and IncA/C. bla $a_{\mathrm{NDM}-1}$ in E. coli on IncFII, whereas in E. cloacae noticed on IncHI2 plasmid. $m c r-$ 1 was recorded among IncFIIK, IncFII, and IncF in E. coli, K. pneumoniae, and E. cloacae. Resistance genes $\left(m c r-1, b l a_{\mathrm{NDM}-1}, b l a_{\mathrm{KPC}-2}\right)$ harboring plasmids are successfully transconjugant to EC-600. A high incidence of ST11 was observed in $K$. pneumoniae carbapenem resistant isolates. While in $E$. coli, multiple STs were identified. However, $m c r-1$ in ST23 was identified for the first time in Anhui Province. Among Enterobacter cloacae, ST270 detected carrying $b l a_{\mathrm{NDM}-1}$. Southern-hybridization confirmed the plasmid sizes $35-150 \mathrm{~kb}$.

Conclusion: This study indicates the co-carrying of $m c r-1, b l a_{\mathrm{KPC}-2,}$, and $b l a_{\mathrm{NDM}-1}$ among clinical isolates, the prevalence of different Enterobacteriaceae STs is alarming, especially in E. coli. Holding such a resistance profile is a threat for humans and animals, which may be transferred between the strains through plasmid transfusion. Persistent control actions are immediately necessary to combat this hazard.

Keywords: ESBL, MBL, KPC2, mcr-1, NDM-1, CTXM-15

\section{Introduction}

The extensive practice of carbapenems in medical treatment and colistin in animal farms has intensified severe community health problems. ${ }^{1}$ Carbapenem resistant Enterobacteriaceae (CRE) comprises various types of bacteria, and each one has its mechanism of drug resistance. ${ }^{2}$ Counting them, the $K$. pneumoniae carbapenem resistance accounts for about sixty percent, followed by Escherichia coli and Enterobacter cloacae. ${ }^{3,4}$ With carbapenemases, bla $a_{\mathrm{KPC}-2}$ and $b l a_{\mathrm{NDM}-1}$ are the maximum predominant 
ones in the K. pneumoniae and carbapenem resistant E. coli, respectively. ${ }^{5,6}$ Even the latest research reports indicate the spread of multiple resistance determinants in a single strain. ${ }^{7,8}$ Worldwide colistin usage in veterinary farms may increase to $67 \%$ by 2030 , estimated mostly by BRICS (Brazil, Russia, India, China, and South Africa). Significant and severe farming processes are essential to increase income and animal protein utilization. ${ }^{9}$ Colistin is another last therapeutic option to combat infectious diseases caused by gram negative multidrug resistant bacilli. ${ }^{10}$

The rising mobile colistin resistant gene $m c r-1$ encodes phosphoethanolamine transferase, vital community health problem, ${ }^{11}$ after its initial discovery in china, the global research reports on $m c r-1$ propagates. Different Enterobacteriaceae species carrying the $m c r-1$ gene on various plasmids have been reported in clinical and veterinary bacterial isolates in Europe, Asia, Africa, South, and North America. $^{12}$ Many countries reported the co-occurring of mcr-1 with many other resistance genes, especially with $b l a_{\mathrm{KPC}-2}$ and $b l a_{\mathrm{NDM}-1}$ in clinical settings and veterinary livestock. ${ }^{13}$ The reports mainly show more than two carbapenem determinants in a single plasmid, thus alarming us for their plasmid nature transmission.

On the other hand, the information on these antimicrobials' susceptibilities on CRE plus colistin are still incomplete. The complete and accurate epidemiological scientific information of each region is critical and essential for future points of view and the proper identification of each resistive determinant. Our study's main aim is to investigate comprehensive and precise epidemiological scientific information of colistin plus carbapenem resistance Enterobacteriaceae.

Overall, in our investigation, 158 carbapenem resistant Enterobacteriaceae (CRE) samples were received from a tertiary A hospital in Hefei, Anhui province, China. To find the epidemiological characteristics of CRE, we performed the antibiotic susceptibility, identification of resistant variants, multilocus sequence typing (MLST), PCR-based replicon typing (PBRT) of resistant determinants, pulse field gel electrophoresis (PFGE), and southern blot hybridization.

\section{Materials and Methods}

\section{Samples Collection Identification and Study Design}

To identify the spread of CRE, especially with mobilized colistin resistance gene $m c r(1-5)$ among medical isolates.
We performed a study in a tertiary A hospital, strains collected from March 2018 to April 2019. One hundred fifty-eight samples, including sputum $(n=95)$, urine $(n=43)$, wound $(n=12)$, and blood $(n=8)$, were collected from the first affiliated hospital of USTC in Hefei Anhui province, China. The bacterial models include $K$. pneumoniae $(n=88)$, E. coli $(n=38), E$. cloacae $(n=26)$, and Serratia marcescens $(n=6)$. All the isolates were grown on MacConkey agar at $37^{\circ} \mathrm{C}$ overnight. The next morning the single colony was selected from MacConkey agar plate and grown on Luria-Bertani (LB) broth 10-12 hours or overnight to identify specific bacteria 16s rRNA gene was screened from LB broth and sequenced. Sequencing data were then analyzed by using BLAST (www.ncbi.nlm.nih.gov/blast) and (www.ezbio cloud.net).

\section{Antimicrobial Susceptibility Testing}

Seventeen different antibiotics were used for the antimicrobial susceptibility testing. Antibiotics included are amikacin (AMK), ampicillin (AMP), aztreonam (ATM), ceftriaxone (CRO), cefuroxime (CXM), ceftazidime (CAZ), ciprofloxacin (CIP), cefazolin (CFZ), ertapenem (ETP), gentamicin (GEN), imipenem (IPM), levofloxacin (LVX), cefepime (FEP), cefotaxime (CTX), meropenem (MEM), tigecycline (TGC), and colistin (CST). The broth microdilution method (BMDM) was used to test all of them. The clinical and Laboratory Standards Institute (CLSI 2019) recommendations were followed for result interpretation. ${ }^{13}$ As the breakpoint value of colistin is missing in CLSI. We consider the European Committee's breakpoint value on Antimicrobials Susceptibility Testing (EUCAST) (www.eucast.org) colistin greater than $2 \mu \mathrm{g} /$ $\mathrm{mL}$. For carbapenem, the breakpoint value was described as a $\mathrm{MIC}$ of $\geq 4 \mu \mathrm{g} / \mathrm{mL}$.

\section{Detection of Antibiotic Resistant Genes (ARGs)}

The boiling method was performed for the extraction of bacterial DNA templates. ${ }^{14}$ Colistin resistant genes for the detection were included $m c r(1-5)$, Carbapemases genes for detection were (bla ${ }_{\mathrm{KPC}}, b l a_{\mathrm{AIM}}, b l a_{\mathrm{OXA}}$, bla $_{\mathrm{DIM}}, b l a_{\mathrm{NDM}}, \quad b l a_{\mathrm{GIM}}$, blaSIM, bla $a_{\mathrm{SPM}}$, bla $a_{\mathrm{VIM}}$, $b l a_{\mathrm{IMP}}$, and $\left.b l a_{\mathrm{GES}}\right)$. Extended-spectrum genes were included ( bla $_{\mathrm{CTX}}, b l a_{\mathrm{TEM}}, b l a_{S \mathrm{HV}}$, bla $_{\mathrm{VEB}}$, and $\left.b l a_{\mathrm{PER}}\right)$ according to the protocols defined previously. ${ }^{15-17}$ The amplified PCR results were directed for sequencing to 
General Biosystems Co., Ltd. (Hefei-China), and the sequencing data was then analyzed and confirmed by using BLAST (www.ncbi.nlm.nih.gov/blast).

\section{Multilocus Sequence Typing (MLST)}

Carbapenem resistant $K$. pneumoniae STs were identified by MLST, with the screening of seven house-keeping genes comprising (gapA, mdh, pgi, infB, phoE, rpoB, and tonB), and were sequenced as defined previously. ${ }^{18}$ The sequencing data was analyzed by the Pasteur online database (www.pas teur.fr/mlst/Kpneumoniae.html). For the identical and proper alleles sequence type identification of $E$. coli, the seven housekeeping genes used were $(a d k, g y r B, i c d, m d h$, fumC, purA, and $\operatorname{rec} A$ ), and the data was analyzed by https://bigsdb.pasteur. fr/Ecoli/ecoli.html. The MLST database (http://pubmlst.org/ Ecloacae/) was used to identify E. cloacae sequence types. The essential seven genes of $E$. cloacae screened and sequenced from the E. cloacae colony were (dnaA, gyrB, leuS, fusA, pyrG, rplB, and rpoB).

\section{PCR Based Replicon Typing (PBRT)}

Among the CRE, the incompatibility of plasmid groups and the plasmid of colistin resistant determinants were identified by performing PCR-based replicon typing (PBRT). KIT 2.0 (DIATHEVA, Italy) was used for the identification of thirty different plasmids; IncHI1, IncHI2, IncI1, IncI2, IncX1, IncX2, IncX3, IncX4, IncL, IncFIIs, IncFIIk, IncFIB-KN, IncFIB-KQ, IncW, IncY, IncP1, IncA/C, IncM, IncN, IncFIA, IncFIC, IncFII, IncB/O, IncT, IncK, IncU, IncR, IncHIB-M, IncFIB-M, and IncFIB were used according to the protocol. ${ }^{19}$

\section{Conjugation Experiment}

To investigate the transferability of resistance determinants, six mcr- 1 resistant strains $(2 \mathrm{~K}$. pneumoniae, 2 E. cloacae, and 2 E. coli), six bla $a_{\mathrm{NDM}-1}$ (4 E. cloacae and $1 \mathrm{~K}$. pneumonia and $1 \mathrm{E}$. coli), and six bla $a_{\mathrm{KPC}-2}$ $K$. pneumoniae resistant strains were selected as donors. The recipient bacteria used for conjugation assays was $E C-600\left(\mathrm{Nal}^{\mathrm{R}}\right.$, $\left.\mathrm{Rif}^{\mathrm{R}}\right)$, according to the protocol as previously defined. ${ }^{20}$ Confirmation of transconjugants was done by antimicrobial susceptibility followed by PCR band recognition and finally confirmed by PBRT.

\section{Pulsed Field Gel Electrophoresis (PFGE) and Southern Hybridization}

To find the genomic similarity and identify the position of transmissible $m c r-1, b l a_{\mathrm{KPC}-2}$, and bla $_{\mathrm{NDM}-1}$, isolates were categorized by S1-PFGE and southern hybridization through a specific probe of $m c r-1, \quad b l a_{\mathrm{KPC}-2}$, and $b l a_{\mathrm{NDM}-1}$. S1 nuclease was used to digest each genome and then examined through PFGE as described previously. ${ }^{21}$ According to the manufacturer's directions, southern hybridization of plasmid DNA was accomplished with a digoxin-labeled $m c r-1, \quad b l a_{\mathrm{KPC}-2}$, and $b l a_{\mathrm{NDM}-1}$ specific probe (Roche Diagnostics, Mannheim, 32 Germany) as previously described. ${ }^{22}$

\section{Results}

\section{Bacterial Isolation and Antimicrobial Susceptibility}

The clinical isolates were collected from various departments, including 51/158 (32.27\%) high prevalence recorded in the respiratory unit, $37 / 158(23.4 \%)$ collected from intensive care unit ICU, $23 / 158$ (14.55\%) from the urinary surgery department, 17/158 (10.75\%) from neurosurgery, 10/158 (6.32\%) from gerontology, 9/158 (5.69\%) from pediatric, $7 / 158(4.43 \%)$ from orthopedic and 4/158 $(2.53 \%)$ from oncology, and the distribution of each bacterial species among the collected samples are listed in the (Supplemental Figure 1). Overall, 158 different bacterial strains were collected from the First Affiliated Hospital of USTC. All the samples were observed to be carbapenem and colistin non-susceptible by phenotypic approach. The frequency rate of each strain found was K. pneumoniae 88/ 158 (55.7\%), E. coli 38/158 (24\%), E. cloacae 26/158 (16.45\%), and $S$. marcescens $6 / 158 \quad(3.79 \%)$ (Supplemental Table 1). The high frequency was observed in sputum $95 / 158(60.12 \%)$, followed by urine $43 / 158$ (27.21\%), wound $12 / 158(7.59 \%)$, and blood was $8 / 158$ (5.06\%) (Supplemental Figure 2). The antimicrobial sensitivity testing for all collected isolates was performed by broth microdilution method against 17 Antibiotics, in which tigecycline was detected as the most susceptible drug having a sensitivity of $93 \%$. Likewise, the resistivity against the meropenem and colistin were $78.8 \%$ and $43.2 \%$, respectively. The sensitivity and resistivity profile for all 17 drugs against collected strain and their MIC values are presented in Table 1. 
Table I Representing MICs

\begin{tabular}{|l|l|l|l|l|l|}
\hline Antibiotics & Mic50 & Mic90 & Range $(\boldsymbol{\mu g} / \mathbf{m L})$ & $\% \mathbf{R}$ & $\% \mathbf{S}$ \\
\hline Amikacin & $>128$ & $>128$ & $\mathrm{I}-128$ & 75.9 & 24.1 \\
\hline Ampicillin & $>128$ & $>128$ & $\mathrm{I}-128$ & 86.1 & 13.9 \\
\hline Aztreonam & $>128$ & $>128$ & $\mathrm{I}-128$ & 92.4 & 7.6 \\
\hline Ceftazidime & $>32$ & $>32$ & $0.25-32$ & 78.9 & 21.1 \\
\hline Ciprofloxacin & $>8$ & $>8$ & $0.06-8$ & 45.3 & 54.7 \\
\hline Ceftriaxone & $>32$ & $>32$ & $0.25-32$ & 84 & 16 \\
\hline Cefotaxime & $>32$ & $>32$ & $0.25-32$ & 86.3 & 13.7 \\
\hline Cefuroxime & $>64$ & $>64$ & $0.5-64$ & 71.4 & 28.6 \\
\hline Cefazolin & $>64$ & $>64$ & $0.5-64$ & 73.8 & 26.2 \\
\hline Ertapenem & $>32$ & $>32$ & $0.5-32$ & 87.5 & 12.5 \\
\hline Cefepime & $>32$ & $>32$ & $0.5-32$ & 91 & 9 \\
\hline Gentamicin & $>128$ & $>128$ & $1-128$ & 77 & 23 \\
\hline Imipenem & $>16$ & $>16$ & $0.125-16$ & 69 & 31 \\
\hline Levofloxacin & $>16$ & $>16$ & $0.125-8$ & 61 & 39 \\
\hline Meropenem & $>16$ & $>16$ & $0.125-16$ & 78.8 & 21.2 \\
\hline Tigecycline & 0.5 & 1 & 0.125 & 7 & 93 \\
\hline Colistin & 4 & 8 & $1-128$ & 43.2 & 56.8 \\
\hline
\end{tabular}

\section{Prevalence of Resistance Determinants in}

\section{$K$. pneumoniae, E. coli, E. cloacae, and}

\section{S. marcescens}

The prevalence of $K$. pneumoniae resistant determinants is shown in (Table 2). In 84/88 (95.4\%), a high prevalence of serine $\beta$-lactamases, producing $K$. Pneumoniae
Carbapenemases bla $\mathrm{KPC}-2_{2}$ has been observed alone or in combination with bla $_{\mathrm{CTX}-\mathrm{M}-15}(47.7 \%)$, fosA3 (14.77\%), $b l a_{\text {OXA-48 }}(3.4 \%)$, and colistin resistant $m c r-1$ (2.2\%). Overall among the CRE, the prevalence rate of the $b l a_{\mathrm{KPC}-2}$ gene was $90.5 \%$.

Concerning the E. coli isolates, the prevalence of bla $_{\mathrm{KPC}-2}$ was $89.4 \%$, combined with the ESBL bla $a_{\mathrm{CTX}-\mathrm{M}-15}$ encoding gene $15.7 \%$. In two $E$. coli isolates, $m c r-1$ was caught in 56 and 57 years old male and female urine samples. fosA 3 and bla $a_{\text {OXA-48 }}$ were observed in four isolates, respectively. The combination of $m c r-1$ and $b l a_{\mathrm{KPC}-2}$ found $10.56 \%$ in E. coli.

Regarding E. cloacae, the prevalence of $b l a_{\mathrm{KPC}-2}$ was detected at $84.6 \%$. $b l a_{\mathrm{KPC}-2}$ plus $b l a_{\mathrm{NDM}-1}$ saw $15.3 \%$, a combination of $b l a_{\mathrm{CTX}-\mathrm{M}-15}$ and $b l a_{\mathrm{KPC}-2}$ noted $30.70 \%$. Six isolates confirming the presence of fos $A 3$, and two isolates have $b l a_{\text {OXA-48. Two }} m c r-1$ detected in a 77 years old male blood sample and 68 years old female sputum sample. Enterobacter cloacae possess the $m c r-1$ plus bla $_{\mathrm{KPC}-2}$ remarked $7.6 \%$.

Three isolates of $S$. marcescens carry bla $_{\mathrm{KPC}-2}$ determinant, respectively, and two of them combined with $b l a_{\mathrm{CTX}-\mathrm{M}-15}$, genes which are spotted in our article are listed in (Supplemental Table 2).

\section{Multilocus Sequence Typing (MLST)}

A high incidence of ST11 was observed in all isolates of CRKP, while in case of $E$. coli the sequence types noticed were ST69 $(n=4)$, ST131 $(n=3), \operatorname{ST} 1193 \quad(n=3)$, ST12 $(n=1), \operatorname{ST} 46(n=1), \operatorname{ST} 57 \quad(n=1), \operatorname{ST} 1196(n=1)$, ST38 $(n=1)$, ST95 $(n=1)$ and ST23 $(n=1)$. Among the Enterobacter cloacae, ST270 was detected only, and the result shown in Table 3.

Table 2 Distribution of Antibiotic Resistance Genes (ARGs)

\begin{tabular}{|c|c|c|c|c|}
\hline Resistant Determinants & $\begin{array}{c}\text { K. pneumonia } \\
(\mathrm{n}=88)\end{array}$ & $\begin{array}{l}\text { E. coli } \\
(n=38)\end{array}$ & $\begin{array}{c}\text { E. cloacae } \\
(n=26)\end{array}$ & $\begin{array}{c}\text { Serratia marcescens } \\
\qquad(n=6)\end{array}$ \\
\hline bla $a_{\mathrm{KPC}-2}(n=143)$ & 84 & 34 & 22 & 3 \\
\hline bla $a_{\text {NDM-I }}(n=6)$ & I & 1 & 4 & - \\
\hline$b l a_{O \times A-48}(n=9)$ & 3 & 4 & 2 & - \\
\hline FosA3 $(n=23)$ & 13 & 4 & 6 & - \\
\hline$m c r-I(n=6)$ & 2 & 2 & 2 & - \\
\hline bla $_{\text {CTXM-15 }}(n=58)$ & 42 & 6 & 8 & 2 \\
\hline
\end{tabular}


Table 3 Distribution of Plasmid Replicons, STs, and Resistant Genes of Eighteen Bacterial Strains

\begin{tabular}{|c|c|c|c|c|c|c|}
\hline Sample & Plasmid/PBRT & Trans-Conjugants & Size (kb) & STs & Strain & Resistant Genes \\
\hline SI53 & IncFIlk(I48bp) & + & 70 & STII & K. pneumonia & mcr-I \\
\hline S39 & IncFIl (292bp) & + & 35 & STII & K. pneumonia & mcr-I \\
\hline S08 & IncFII(292bp) & + & 35 & ST270 & E. cloacae & mcr-I \\
\hline SO5 & IncFIlk(63 Ibp) & + & 120 & ST270 & E. cloacae & mcr-I \\
\hline S319 & IncF (683bp) & + & 70 & STI3I & E. coli & mcr-I \\
\hline S47 & $\operatorname{lncF}(683 \mathrm{bp})$ & + & 70 & ST23 & E. coli & mcr-I \\
\hline S19 & IncFII (288bp) & + & 70 & ST23 & E. coli & $b l a_{N D M-I}$ \\
\hline S30 & IncFII (288bp) & + & 70 & STII96 & E. coli & bla $_{\text {NDM-I }}$ \\
\hline S168 & IncHI2 (308bp) & + & 120 & ST270 & E. cloacae & $b^{\prime} a_{\text {NDM-I }}$ \\
\hline S69 & IncHI2 (308bp) & + & 120 & ST270 & E. cloacae & $b l a_{N D M-I}$ \\
\hline S194 & IncHI2 (308bp) & + & 120 & ST270 & E. cloacae & bla $_{\text {NDM-I }}$ \\
\hline S74 & IncHI2 (308bp) & + & 120 & ST270 & E. cloacae & $b l a_{N D M-1}$ \\
\hline S29 & $\operatorname{lncR}(248 b p)$ & + & 100 & STII & K. pneumonia & $b l a_{\mathrm{KPC}-2}$ \\
\hline $\mathrm{SI3}$ & IncFII(288bp) & + & 35 & STII & K. pneumonia & $b l a_{\mathrm{KPC}-2}$ \\
\hline S25 & IncA/C (4|8bp) & + & 50 & STII & K. pneumonia & $b l a_{\mathrm{KPC}-2}$ \\
\hline SI03 & IncFII(288bp) & + & 35 & STII & K. pneumonia & $b l a_{\mathrm{KPC}-2}$ \\
\hline S137 & IncFIlk(63 Ibp) & + & 70 & STII & K. pneumonia & $b l a_{\mathrm{KPC}-2}$ \\
\hline SI49 & IncFII(288bp) & + & 35 & STII & K. pneumonia & $b l a_{\mathrm{KPC}-2}$ \\
\hline
\end{tabular}

\section{Plasmid Replicon Typing (PBRT)}

Among $158 \mathrm{CRE}$ isolates, seven different types of plasmid replicons were detected. K. pneumoniae carrying IncFIIK, IncFII, IncA/C, and IncR were found in $b l a_{\mathrm{KPC}-2}$ positive isolates, while $m c r-1$ producers among $K$. pneumoniae were detected on IncFIIk and IncFII. Enterobacter cloacae were carrying $b l a_{\mathrm{NDM}-1}$ on IncHI2, whereas $m c r-1$ on IncF and IncFIIK. E. coli took $m c r-1$ on IncF type replicon however, $b l a_{\mathrm{NDM}-1}$ on IncFII. The complete profile is listed in Table 3.

\section{Conjugation}

We performed a conjugation experiment for all resistance genes to detect resistance genes' transformability harboring plasmids $\left(m c r-1, b l a_{\mathrm{NDM}-1}, b l a_{\mathrm{KPC}-2}\right)$. Harboring plasmids are successfully trans-conjugant to $E C-600\left(\mathrm{Nal}^{\mathrm{R}}\right.$, $\left.\mathrm{Rif}^{\mathrm{R}}\right)$. The conjugation was confirmed by PCR-based replicon typing (PBRT) of the trans-conjugants, and the result was mention in Table 3. For further conformation, the resistance genes ( $\left.m c r-1, \quad b l a_{\mathrm{NDM}-1}, \quad b l a_{\mathrm{KPC}-2}\right)$ specific plasmid PCR were performed, and the gene was detected in trans-conjugants.

\section{SI-PFGE and Southern Blot}

S1-PFGE further confirmed that all the strains have several plasmids, varying in size and ranging from $35 \mathrm{~kb}-150 \mathrm{~kb}$ (Supplemental Figures 3-5). Southern blotting confirmed that the $m c r-1, b l a_{\mathrm{KPC}-2}$ and $b l a_{\mathrm{NDM}-1}$ genes regained from these isolates were located on the given six dissimilar plasmid types, as shown in Table 3.

\section{Discussions}

The present article focuses on the incidence of $\mathrm{mcr}-1$ combined with other $\beta$-lactamases resistance genes, especially with $b l a_{\mathrm{KPC}-2,}, b l a_{\mathrm{NDM}-1 \text {, }}$ and $b l a_{\mathrm{CTX}-\mathrm{M}}$ in E. coli, K. pneumoniae, Serratia marcescens, and Enterobacter cloacae, and previously stated by many countries. ${ }^{23-25,26}$ We specified information on the antibiotics resistance profiles, STs, plasmid replicons profiles, PFGE, and southern blotting of strains having $m c r-1, b l a_{\mathrm{KPC}-2}$, and $b l a_{\mathrm{NDM}-1}$. 
As far as we know, this report is the initial article associating the carriage of $m c r-1$ with $b l a_{\mathrm{KPC}-2}, b l a_{\mathrm{NDM}-1}$, and $b l a_{C T X-M}$ among the CRE in clinical settings from Anhui province, China.

The extensive use of colistin in livestock is mainly attributed to the spread of colistin resistance determined $m c r-1$, threatening the worldwide distribution of colistin efficiency. The rise of $m c r-1$, mostly in E. coli and $K$. pneumoniae, is of specific concern. To control the spread of colistin resistance from May 1, 2017, the china government banned colistin in livestock. ${ }^{27,28}$ Many reports in china have previously reported the dissemination of mcr-1 mainly associated with animal origin. Cong Shen reported a study ${ }^{29}$ on the prevalence of $m c r-1$ from animal origin pigs $308 / 684$ (45\%), and the plasmids carrying was reported in IncX4, IncI2, and IncHI2. Another study by $\mathrm{X}$-Zhang reported ${ }^{30}$ a very high prevalence of colistin resistance in Jiangsu province, associated with animal origin pigs $303 / 440(68.86 \%)$, chickens $388 / 443$ (87.5\%), and cattle's $30 / 42(71.43 \%)$. A study conducted by Liu et $\mathrm{al}^{31}$ on clinical samples in five different china provinces reported 16/1322 (1\%) mcr-1 in human hospitalized patients. In our study, the dissemination of $m c r-1$ is $6 /$ $158(3.79 \%)$, a little higher than previously reported. The possible reason for the difference between positive isolates in clinical and animal settings is that $m c r-1$ mediated colistin resistance started in the animal's origin and successively extend to humans. The use of colistin in hospital settings is infrequent but still the best option of treatment for CRE infections.

In the production of livestock and poultry animals, china is the world's leading country. In 2014 china only produces 56.7 million tons of poultry and 17.5 million tons of pigs, $90 \%$ of the production was use internally, and about $10 \%$ for export. The prices of veterinary medicines rise from \$20.1 billion in 2011 to $\$ 43$ billion in 2019. In the agriculture sector, China is also the world's largest country using colistin. ${ }^{31}$ The total requirement for colistin use in agriculture globally in 2015 was 11,942 tons per annum, with total revenue of $\$ 229.5$ million and expected to rise 16,500 tons by the end of 2021 with a $4.75 \%$ annual growth rate. The top ten companies producing colistin, including eight from China, $73.1 \%$, were produced in Asia, and $28.7 \%$ were transferred to Europe. To promote growth and health in fish farms, colistin sulphate combined with other antibiotics in China's use as a food diet31. Production of such a high level of colistin is directly proportional to the stress in the veterinary environment and provides a favorable condition for the strains having $m c r-1$.

The world's topmost antimicrobials are utilized in china $^{32}$ The high practice of antimicrobials may activate the rise of antimicrobial resistance AMR. Mainly resistance of $\beta$-lactam and colistin resistance reported worldwide. ${ }^{33-35}$ Recently, plasmid mediated colistin resistant genes have been extensively exposed. ${ }^{36-43}$ We screened 158 MDR Enterobacteriaceae strains isolated from the First Affiliated Hospital of USTC in Anhui province for $m c r-1$ to $m c r-5$ in human clinical samples. The only $m c r-1$ gene was isolated in combination with $b l a_{K P C-2}$ and $b l a_{\mathrm{NDM}-1}$. Our research project identifies the carriage rate of $m c r-1$ (6/158) in humans is not so high but primarily occurred in combination with other resistive genes. The frequency of $\beta$ lactamases is very high in our report supporting the data published previously. ${ }^{44}$ The frequency rate of $m c r-1$ in Enterobacteriaceae among the clinical strains is relatively low in many countries ${ }^{25} \mathrm{We}$ are reporting the ratio of $m c r-1$ $(n=6) 3.7 \%$, which is relatively high compared to other provinces. In Changsha, Hunan province, $m c r-1$ was noticed in three $(2.1 \%)$ of the 144 E. coli clinical isolates. ${ }^{45}$ As compared with an animal origin, especially in pigs, the rate of $m c r-1$ is $75 \%$, much higher than clinical findings. ${ }^{46}$

The extreme incidence of $b l a_{\mathrm{KPC}-2}$, blaESBLs, and $b l a_{\mathrm{NDM}-1}$, was reliable with the earlier reports, ${ }^{47}$ representing the common co-carrying of antimicrobials resistance genetic factor, which might prime to the development of deadly $K$. pneumoniae toxicities. Amongst them, the relatively extreme occurrence of blaESBL with $b l a_{\mathrm{KPC}-2}$ in our finding suggests critical intimidations to public health since several duplicates of $b l a_{\mathrm{CTX}-\mathrm{M}}$ and $b l a_{\mathrm{KPC}-2}$ within plasmids might be joined and circulated into the chromosome, the percentage of $b l a_{\mathrm{CTX}-\mathrm{M}-15}$ in our project is $36.7 \%(58 / 158)$ which is relatively low as compared to previous reports published from many countries around the globe. ${ }^{48,49}$ In that situation, the rise of such isolates would be horizontally and vertically quicker inside clinics. Until now, the co-prevalence of $b l a_{\mathrm{CTX}-\mathrm{M}-15}$ and $b l a_{\mathrm{KPC}-2}$ was previously noted in K. pneumoniae. ${ }^{50}$ Primarily, we instigate a high occurrence of $f o s A 3(14.7 \%)$ plus bla $a_{\mathrm{KPC}-2}$, producing $K$. pneumoniae. FosA3 has been testified to be chromosomally programmed by medically relevant Gram negative bacteria and enhances inherent fosfomycin resistance, and the high prevalence reported previously. ${ }^{51}$ Additionally, the reports showing that the extensive 
dissemination of fos $A 3$ directed that fosfomycin must be vigilantly consumed for handling CRKP diseases. ${ }^{52}$

Plasmids are extrachromosomal DNA, basically demonstrating the main reservoirs for the horizontal spread of antibiotic resistance between microorganisms. ${ }^{53}$ So far, various plasmids have recognized the carrier for the incidence of carbapenemases in blaESBLs and blaMBLs. ${ }^{54}$ The excessive dominance of IncFII, IncFIIk, and IncR plasmid replicons in our report is aware of the importance of realizing antibiotics resistance observation since IncF type plasmids are intensely disseminated carriers for resistant causes in Enterobacteriaceae. In contrast, some studies stated the prevalence of $b l a_{\mathrm{ndm}-1}$ on IncFII while the $m c r-1$ on IncX4 type plasmid was originating from animal reservoirs. ${ }^{55,56}$ Furthermore, the IncR plasmid is a significant reservoir of many antibiotics resistance in Enterobacteriaceae isolates since the preserved IncR backbones contain the multidrug resistant (MDR) sequences. ${ }^{57}$ Furthermore, IncFIIk plasmids were described to be related to the mainstream of the antimicrobial resistance genes detected more frequently in our study. ${ }^{58}$

The extension of ST11 for the $b l a_{\mathrm{KPC}-2}$ carrying $K$. pneumoniae was in the union as according to the earlier articles representing that, ST11 is the main epidemic clone among $K$. pneumonia. ${ }^{59}$ In our finding, to the best of our knowledge, we investigate for the first time the occurrence of multidrug resistant $E$. coli ST23, isolated from the 61 years old female carrying $m c r-1$, bla $a_{\mathrm{KPC}-2}, b l a_{\mathrm{NDM}-1}$ plus $b l a_{\mathrm{CTX}-\mathrm{M}-15}$. Generally, in our study, we experienced $b l a_{\mathrm{KPC}-2}$ in different sequence types of Escherichia coli manly with $b l a_{\mathrm{CTXM}}$ or $b l a_{\mathrm{NDM}-1}$, specifically $b l a_{\mathrm{KPC}-2}$ plus bla $a_{\mathrm{NDM}-1}$ in E. coli $\mathrm{ST} 12$ and ST57 have not been reported previously from Anhui province. We also report the triple carrying of $K$. pneumoniae $m c r-1$, bla $a_{\mathrm{KPC}-2}$ plus $b l a_{\mathrm{CTXM}}$ in ST11 on IncFIIk 70kb plasmid replicon and other $m c r-1$ on IncFII $35 \mathrm{~kb}$. Both of them are isolated from 61 years old female sputum samples and 80 years old female blood samples. A study done in Brazil on clinical isolates shows $m c r-1$ plus $b l a_{\mathrm{kpc}-2}$ in sequence type $392 .{ }^{60}$

As we report a high incidence of Multidrug resistance Enterobacteriaceae, we have a valuable suggestion. Awareness is needed while handling the resistance cases of blaESBLs, blaMBLs, and colistin. Alertness is needed in hospital settings and food producing animal farms because $m c r-1$, combined with other resistive genes, is a risk to human health. The animals transmit these resistive determinants more frequently and thus might enter to human diet chain very quickly.

\section{Conclusion}

Our study indicates the high incidence of multidrug resistance Enterobacteriaceae, $m c r-1$ carrying with ESBL $b l a_{\mathrm{CTX}-\mathrm{M}-15}$ and blaMBLs $b l a_{\mathrm{NDM}-1}$, and $b l a_{\mathrm{KPC}-2}$ clinical samples in Anhui China. Holding such a resistance profile is an excellent threat for humans and animals, which may be transferred between the same strains and other strains through plasmid transfusion. Need high vigilance for handling such resistive profiles to control the prevalence of such resistant genes and the future world's life. The spread of $b l a_{\mathrm{KPC}-2}$ in different sequence types of $E$. coli and the occurrence of $b l a_{\mathrm{NDM}-1}$ in E. cloacae is alarming and painful, well organized, and persistent control actions required that are immediately necessary.

\section{Abbreviations}

MLST, Multilocus sequence typing; PFGE, Pulse field gel electrophoresis; PBRT, PCR based replicon typing; MCR, mobilized colistin resistance gene.

\section{Statement of Ethics}

This study has been approved (approval number 2020KY191) by the ethical committee of the First Affiliated Hospital of the university of science and technology of China (USTC).

\section{Acknowledgment}

The authors are grateful to the Institute of Life Sciences of Anhui University for publishing this work.

\section{Funding}

This work was supported by grants from the National Natural Science Foundation of China (31970103, 32071215). The funder has no role in the experimental process and paper publication.

\section{Disclosure}

Dr Muhammad Shafiq is now affiliated with Cell Biology and Genetics Department, Shantou University Medical College, Shantou 515041, China. The authors declare that they have no conflicts of interest for this work.

\section{References}

1. World Health Organization. World health statistics 2015. World Health Organization; 2015.

2. Cerqueira GC, Earl AM, Ernst CM, et al. Multi-institute analysis of carbapenem resistance reveals remarkable diversity, unexplained mechanisms, and limited clonal outbreaks. Proc Nat Acad Sci. 2017;114(5):1135-1140. doi:10.1073/pnas.1616248114 
3. Zhang Y, Wang Q, Yin Y, et al. Epidemiology of carbapenem-resistant Enterobacteriaceae infections: report from the China CRE Network. Antimicrob Agents Chemother. 2018;62(2).

4. Grundmann H, Glasner C, Albiger B, et al. Occurrence of carbapenemase-producing Klebsiella pneumoniae and Escherichia coli in the European survey of carbapenemase-producing Enterobacteriaceae (EuSCAPE): a prospective, multinational study. Lancet Infect Dis. 2017;17(2):153-163. doi:10.1016/S1473-3099(16) 30257-2

5. Munoz-Price LS, Poirel L, Bonomo RA, et al. Clinical epidemiology of the global expansion of Klebsiella pneumoniae carbapenemases. Lancet Infect Dis. 2013;13(9):785-796. doi:10.1016/S1473-3099(13) 70190-7

6. Khan AU, Maryam L, Zarrilli R. Structure, genetics and worldwide spread of New Delhi metallo- $\beta$-lactamase (NDM): a threat to public health. BMC Microbiol. 2017;17(1):1-12.

7. Cheng L, Cao XL, Zhang ZF, et al. Clonal dissemination of KPC-2 producing Klebsiella pneumoniae ST11 clone with high prevalence of oqxAB and rmtB in a tertiary hospital in China: results from a 3-year period. Ann Clin Microbiol Antimicrob. 2016;15(1):1-8. doi:10.1186/s12941-015-0109-x

8. Boeckel T, Van Brower C, Gilbert M, et al. Global trends in antimicrobial use in food animals. Proc Nat Acad Sci. 2015;112:5649-5654. doi:10.1073/pnas.1503141112

9. Skov RL, Monnet DL. Plasmid-mediated colistin resistance (mcr-1 gene): three months later, the story unfolds. Eurosurveillance. 2016;21(9):30155. doi:10.2807/1560-7917.ES.2016.21.9.30155

10. Olaitan AO, Morand S, Rolain JM. Emergence of colistin-resistant bacteria in humans without colistin usage: a new worry and cause for vigilance. Elsevier; 2016.

11. Gao R, Hu Y, Li Z, et al. Dissemination and mechanism for the MCR-1 colistin resistance. PLoS Pathog. 2016;12(11):e1005957.

12. Vasquez AM. Investigation of Escherichia coli harboring the mcr-1 resistance gene-Connecticut, 2016. MMWR Morb Mortal Wkly Rep. 2016;65. doi:10.15585/mmwr.mm6536e3

13. Clinical, M100 LSIJCs. Performance standards for antimicrobial susceptibility testing. Wayne, PA: Clinical and Laboratory Standards Institute; 2017.

14. Ahmed OB, Dablool AS. Quality improvement of the DNA extracted by boiling method in gram negative bacteria. Int J Bioassays. 2017;6(4).

15. Dallenne C, Da Costa A, Decré D, Favier C, Arlet GJ. Development of a set of multiplex PCR assays for the detection of genes encoding important $\beta$-lactamases in Enterobacteriaceae. $J$ Antimicrob Chemother. 2010;65(3):490-495. doi:10.1093/jac/dkp498

16. Poirel L, Walsh TR, Cuvillier V, Nordmann P. Multiplex PCR for detection of acquired carbapenemase genes. Diagnostic Microbiol Infect Dis. 2011;70(1):119-123. doi:10.1016/j. diagmicrobio.2010.12.002

17. Nakamura G, Wachino JI, Sato N, et al. Practical agar-based disk potentiation test for detection of fosfomycin-nonsusceptible Escherichia coli clinical isolates producing glutathione S-transferases. J Clin Microbiol. 2014;52(9):3175-3179. doi:10.1128/JCM.01094-14

18. Wang Y, Tian GB, Zhang R, et al. Prevalence, risk factors, outcomes, and molecular epidemiology of mcr-1-positive Enterobacteriaceae in patients and healthy adults from China: an epidemiological and clinical study. Lancet Infect Dis. 2017;17(4):390-399. doi:10.1016/ S1473-3099(16)30527-8

19. Zhou H, Zhang K, Chen W, et al. Epidemiological characteristics of carbapenem-resistant Enterobacteriaceae collected from 17 hospitals in Nanjing district of China. Antimicrob Resist Infect Control. 2020;9 (1): $1-10$.

20. Shafiq M, Huang J, Rahman SU, et al. High incidence of multidrug-resistant Escherichia coli coharboring mcr-1 and blaCTX-M-15 recovered from pigs. Infection Drug Resist. 2019;12:2135. doi:10.2147/IDR.S209473
21. Li X, Mu X, Zhang P, et al. Detection and characterization of a clinical Escherichia coli ST3204 strain coproducing NDM-16 and MCR-1. Infect Drug Resist. 2018;11:1189.

22. Cao L, Li X, Xu Y, Shen J. Prevalence and molecular characteristics of mcr-1 colistin resistance in Escherichia coli: isolates of clinical infection from a Chinese University Hospital. Infect Drug Resist. 2018;11:1597. doi:10.2147/IDR.S166726

23. Webb HE, Granier SA, Marault M, et al. Dissemination of the mcr-1 colistin resistance gene. Lancet Infect Dis. 2016;16(2):144-145. doi:10.1016/S1473-3099(15)00538-1

24. Tse H, Yuen KY. Dissemination of the mcr-1 colistin resistance gene. Lancet Infect Dis. 2016;16(2):145-146. doi:10.1016/S1473-3099(15) 00532-0

25. Huang H, Dong N, Shu L, et al. Colistin-resistance gene mcr in clinical carbapenem-resistant Enterobacteriaceae strains in China, 2014-2019. Emerg Microbes Infect. 2020;9(1):237-245. doi: $10.1080 / 22221751.2020 .1717380$

26. Wang Q, Wang X, Wang J, et al. Phenotypic and genotypic characterization of carbapenem-resistant Enterobacteriaceae: data from a longitudinal large-scale CRE study in China (2012-2016). Clin Infect Dis. 2018;67(suppl_2):S196-S205. doi:10.1093/cid/ciy660

27. Suay-García B, Pérez-Gracia MT. Present and future of carbapenem-resistant Enterobacteriaceae (CRE) infections. Antibiotics. 2019;8(3):122. doi:10.3390/antibiotics8030122

28. Hemarajata P, Humphries RM. Ceftazidime/avibactam resistance associated with L169P mutation in the omega loop of KPC-2. J Antimicrob Chemother. 2019;74(5):1241-1243. doi:10.1093/jac/ dkz026

29. Shen C, Zhong LL, Yang Y, et al. Dynamics of mcr-1 prevalence and mcr-1-positive Escherichia coli after the cessation of colistin use as a feed additive for animals in China: a prospective cross-sectional and whole genome sequencing-based molecular epidemiological study. Lancet Microbe. 2020;1(1):e34-e43.

30. Zhang X, Zhang B, Guo Y, et al. Colistin resistance prevalence in Escherichia coli from domestic animals in intensive breeding farms of Jiangsu Province. Int J Food Microbiol. 2019;291:87-90. doi:10.1016/j.ijfoodmicro.2018.11.013

31. Liu YY, Wang Y, Walsh TR, et al. Emergence of plasmid-mediated colistin resistance mechanism MCR-1 in animals and human beings in China: a microbiological and molecular biological study. Lancet Infect Dis. 2016;16(2):161-168. doi:10.1016/S1473-3099(15)004247

32. Collignon P, Voss A. China, what antibiotics and what volumes are used in food production animals? 2015.

33. Bai L, Hurley D, Li J, et al. Characterisation of multidrug-resistant Shiga toxin-producing Escherichia coli cultured from pigs in China: co-occurrence of extended-spectrum $\beta$-lactamase-and mcr-1-encoding genes on plasmids. Int J Antimicrob Agents. 2016;48(4):445-448. doi:10.1016/j.ijantimicag.2016.06.021

34. Ali T, Ur Rahman S, Zhang L, et al. Characteristics and genetic diversity of multi-drug resistant extended-spectrum beta-lactamase (ESBL)-producing Escherichia coli isolated from bovine mastitis. Oncotarget. 2017;8(52):90144.

35. Nakayama T, Kumeda Y, Kawahara R, Yamaguchi T, Yamamoto Y. Carriage of colistin-resistant, extended-spectrum $\beta$-lactamaseproducing Escherichia coli harboring the mor-1 resistance gene after short-term international travel to Vietnam. Infect Drug Resist. 2018;11:391.

36. Kraemer JG, Pires J, Kueffer M, et al. Prevalence of extendedspectrum $\beta$-lactamase-producing Enterobacteriaceae and MethicillinResistant Staphylococcus aureus in pig farms in Switzerland. Sci Total Environ. 2017;603:401-405. doi:10.1016/j. scitotenv.2017.06.110

37. Liu X, Liu H, Wang L, et al. Molecular characterization of extendedspectrum $\beta$-lactamase-producing multidrug resistant Escherichia coli from swine in Northwest China. Front Microbiol. 2018;9:1756. 
38. Huang IF, Lee WY, Wang JL, et al. Fecal carriage of multidrug-resistant Escherichia coli by community children in southern Taiwan. BMC Gastroenterol. 2018;18(1):86. doi:10.1186/s12876018-0807-x

39. Xavier BB, Lammens C, Ruhal R, et al. Identification of a novel plasmid-mediated colistin-resistance gene, mcr-2, in Escherichia coli, Belgium, June 2016. Euro Surveillance. 2016;21(27):30280. doi:10.2807/1560-7917.ES.2016.21.27.30280

40. Carattoli A, Villa L, Feudi C, et al. Novel plasmid-mediated colistin resistance mcr-4 gene in Salmonella and Escherichia coli, Italy 2013, Spain and Belgium, 2015 to 2016. Euro Surveillance. 2017;22 (31):30589. doi:10.2807/1560-7917.ES.2017.22.31.30589

41. Borowiak M, Fischer J, Hammerl JA, Hendriksen RS, Szabo I, Malorny BJ. Identification of a novel transposon-associated phosphoethanolamine transferase gene, mcr-5, conferring colistin resistance in d-tartrate fermenting Salmonella enterica subsp. enterica serovar Paratyphi B. J Antimicrob Chemother. 2017;72 (12):3317-3324. doi:10.1093/jac/dkx327

42. Yang YQ, Li YX, Lei CW, Zhang AY, Wang HN. Novel plasmid-mediated colistin resistance gene mcr-7.1 in Klebsiella pneumoniae. J Antimicrob Chemother. 2018;73(7):1791-1795. doi:10.1093/jac/dky111

43. Wang X, Wang Y, Zhou Y, et al. Emergence of a novel mobile colistin resistance gene, mcr-8, in NDM-producing Klebsiella pneumoniae. Emerg Microbes Infect. 2018;7(1):1-9.

44. Zhang R, Liu L, Zhou H, et al. Nationwide surveillance of clinical carbapenem-resistant Enterobacteriaceae (CRE) strains in China. EBioMedicine. 2017;19:98-106. doi:10.1016/j.ebiom.2017.04.032

45. Zhong YM, Liu WE, Zheng ZF. Epidemiology and molecular characterization of mcr-1 in Escherichia coli recovered from patients with bloodstream infections in Changsha, central China. Infect Drug Resist. 2019;12:2069.

46. Lai CC, Lin YT, Lin YT, et al. Clinical characteristics of patients with bacteraemia due to the emergence of mcr-1-harbouring Enterobacteriaceae in humans and pigs in Taiwan. Int J Antimicrob Agents. 2018;52(5):651-657. doi:10.1016/j.ijantimicag.2018.08.015

47. Liu Y, Wan LG, Deng Q, et al. First description of NDM-1-, KPC-2-, VIM-2-and IMP-4-producing Klebsiella pneumoniae strains in a single Chinese teaching hospital. Epidemiol Infect. 2015;143 (2):376-384. doi:10.1017/S0950268814000995

48. Huang W, Wang G, Sebra R, et al. Emergence and evolution of multidrug-resistant Klebsiella pneumoniae with both blaKPC and blaCTX-M integrated in the chromosome. Antimicrob Agents Chemother. 2017;61(7).
49. Zhuo C, Li XQ, Zong ZY, Zhong NS. Epidemic plasmid carrying bla CTX-M-15 in Klebsiella penumoniae in China. PloS One. 2013;8(1): e52222.

50. Yu F, Hu L, Zhong Q, et al. Dissemination of Klebsiella pneumoniae ST11 isolates with carbapenem resistance in integrated and emergency intensive care units in a Chinese tertiary hospital. $\mathrm{J} \mathrm{Med}$ Microbiol. 2019;68(6):882-889. doi:10.1099/jmm.0.000981

51. Ito R, Mustapha MM, Tomich AD, et al. Widespread fosfomycin resistance in Gram-negative bacteria attributable to the chromosomal fosA gene. MBio. 2017;8(4).

52. Chen J, Wang D, Ding Y, Zhang L, Li X. Molecular epidemiology of plasmid-mediated fosfomycin resistance gene determinants in Klebsiella pneumoniae Carbapenemase-Producing Klebsiella pneumoniae Isolates in China. Microb Drug Resist. 2019;25(2):251-257. doi:10.1089/mdr.2018.0137

53. Carattoli AJ. Plasmids and the spread of resistance. Int $\mathrm{J} \mathrm{Med}$ Microbiol. 2013;303(6-7):298-304. doi:10.1016/j.ijmm.2013.02.001

54. Zurfluh K, Klumpp J, Nüesch-Inderbinen M, Stephan R. Full-length nucleotide sequences of mcr-1-harboring plasmids isolated from extended-spectrum- $\beta$-lactamase-producing Escherichia coli isolates of different origins. Antimicrob Agents Chemother. 2016;60 (9):5589-5591. doi:10.1128/AAC.00935-16

55. Potter RF, D'Souza AW, Dantas G. The rapid spread of carbapenem-resistant Enterobacteriaceae. Drug Resistance Updates. 2016;29:30-46. doi:10.1016/j.drup.2016.09.002

56. Peng Z, Li X, Hu Z, et al. Characteristics of Carbapenem-Resistant and Colistin-Resistant Escherichia coli Co-Producing NDM-1 and MCR-1 from Pig Farms in China. Microorganisms. 2019;7(11):482.

57. Jing Y, Jiang X, Yin Z, et al. Genomic diversification of IncR plasmids from China. $J$ Global Antimicrob Resist. 2019;19:358-364. doi:10.1016/j.jgar.2019.06.007

58. Musicha P, Msefula CL, Mather AE, et al. Genomic analysis of Klebsiella pneumoniae isolates from Malawi reveals acquisition of multiple ESBL determinants across diverse lineages. J Antimicrob Chemother. 2019;74(5):1223-1232. doi:10.1093/jac/dkz032

59. Chi X, Hu G, Xu H, et al. Genomic analysis of a KPC-2-producing Klebsiella pneumoniae ST11 outbreak from a teaching hospital in Shandong Province, China. Infect Drug Resist. 2019;12:2961.

60. Aires CAM, da Conceição-neto OC, e Oliveira TRT, et al. Emergence of the plasmid-mediated mcr-1 gene in clinical KPC-2-producing Klebsiella pneumoniae sequence type 392 in Brazil. Antimicrob Agents Chemother. 2017;61(7). doi:10.1128/AAC.00317-17
Infection and Drug Resistance

\section{Publish your work in this journal}

Infection and Drug Resistance is an international, peer-reviewed openaccess journal that focuses on the optimal treatment of infection (bacterial, fungal and viral) and the development and institution of preventive strategies to minimize the development and spread of resistance. The journal is specifically concerned with the epidemiology of antibiotic resistance and the mechanisms of resistance development and diffusion in both hospitals and the community. The manuscript management system is completely online and includes a very quick and fair peerreview system, which is all easy to use. Visit http://www.dovepress.com/ testimonials.php to read real quotes from published authors. 